\title{
A Comparative Study of [F-18] Florbetaben (FBB) PET Imaging, Pathology, and Cognition between Normal and Alzheimer Transgenic Mice
}

\author{
Ngeemasara Thapa ${ }^{1, *}$, Young-Jin Jeong ${ }^{2,3, * * *}$, Hyeon Kang ${ }^{3, *}$, Go-Eun Choi ${ }^{4, * * *}$, \\ Hyun-Jin Yoon ${ }^{2,3, * *}$ and Do-Young Kang ${ }^{2,3, \dagger ; * * *}$ \\ ${ }^{1}$ Department of Health care and Science, College of Health Sciences, Dong-A University, Busan 49315, Korea \\ ${ }^{2}$ Department of Nuclear Medicine, Dong-A University Medical Center, Dong-A University \\ College of Medicine, Busan 49201, Korea \\ ${ }^{3}$ Institute of Convergence Bio-Health, Dong-A University, Busan 49315, Korea \\ ${ }^{4}$ Department of Clinical Laboratory Science, College of Health Sciences, \\ Catholic University of Pusan, Busan 46252, Korea
}

\begin{abstract}
Alzheimer's disease (AD) is highly prevalent in dementia, with no specifically effective treatment having yet been discovered. Amyloid plaques are one of the key hallmarks of AD. Transgenic mouse models exhibiting Alzheimer's disease-like pathology have been widely used to study the pathophysiology of Alzheimer's disease. In this study, we showed an age-dependent correlation between cognitive function, pathological findings, and [F-18] Florbetaben (FBB) PET images. Nineteen transgenic mice (12 with $A D, 7$ with controls) were used for this study. We observed an increase in $\beta$-Amyloid deposition $(\mathrm{A} \beta)$ in brain tissue and [F-18] FBB amyloid PET imaging in the AD group. The [F-18] FBB data showed a mildly negative trend with cognitive function. Pathological findings were negatively correlated with cognitive functions. These finding suggests that amyloid beta deposition can be well-monitored with [F-18] FBB PET and a decline in cognitive function is related to the increase in amyloid plaque burden.
\end{abstract}

Key Words: [F-18] FBB, Tg2576 mouse, Alzheimer's disease, $\beta$-Amyloid, PET imaging

\section{INTRODUCTION}

Alzheimer's disease (AD) is an age-dependent (Villemagne et al., 2008) slow progressive neurodegenerative disease (Tijms et al., 2018), and is the most dominant cause of dementia, contributing up to $60 \sim 70 \%$ of cases. The incidence of AD increases with age, and approximately 500,000 people are diagnosed with this disease each year (Klunk et al.,
2003). The cerebral cortex and hippocampus area are densely affected by $\mathrm{AD}$ (Zhang et al., 2018). AD weakens cognitive function (Ameen-Ali et al., 2017), affects memory, leads to physical impairment, and reduces the ability to maintain a normal lifestyle (Drzezga, 2010). $\beta$-Amyloid (A $\beta$ ) plaques and neurofibrillary tangles are the two most common hallmarks of Alzheimer's disease (Drzezga, 2010; Holtzman et al., 2011), and the deposition of these $A \beta$ plaques may be the foremost pathology of $\mathrm{AD}$, even before the onset of cognitive

Received: February 8, 2019 / Accepted: March 5, 2019

*Graduate student, ${ }^{* *}$ Researcher, ${ }^{* * *}$ Professor.

†Corresponding author: Do-Young Kang. Department of Nuclear Medicine, Dong-A University Medical Center, Dong-A University College of Medicine, \#26 Daesingongwon-ro, Seo-gu, Busan 49201, Korea.

Tel: +82-51-240-5630, Fax: +82-51-242-7237, e-mail: dykang@dau.ac.kr

(C) The Korean Society for Biomedical Laboratory Sciences. All rights reserved.

(c) This is an Open Access article distributed under the terms of the Creative Commons Attribution Non-Commercial License (http://creativecommons.org/licenses/by-nc/3.0/) which permits unrestricted non-commercial use, distribution, and reproduction in any medium, provided the original work is properly cited. 
decline (Klunk et al., 2003). One third of cognitively normal adults aged 65 years and above has $A \beta$ plaque deposition similar to AD patients (Rowe et al., 2013; Molinuevo et al., 2018). Autopsy studies also show the prevalence of $A \beta$ plaque in older adults with normal cognition (Aizenstein et al., 2008). Although some quantities of $A \beta$ plaques can be found in cognitively normal elderly people (Aizenstein et al., 2008), AD diagnosis is made with the presence of both plaques and cognitive impairment (Khachaturian, 1985; Hsiao et al., 1996). The need for research studies in AD are of great importance due to the current lack of effective treatment and proper prognosis of this disease (Elder et al., 2010).

The transgenic mouse model has been used extensively in $\mathrm{AD}$ research. In the current study, we investigated the correlation between age-dependent depositions of $\mathrm{A} \beta$ plaques and cognitive decline in varying age groups of $\mathrm{Tg} 2576$ mouse model of Alzheimer's disease. The Tg2576 mouse model starts to develop $A \beta$ plaque depositions from 9 to 12 months of age (Kawarabayashi et al., 2001) and is associated with cognitive impairment (Hsiao et al., 1996); thus it is an ideal model to study AD. Human PET imaging using molecular tracers are used for in vivo assessment of $\mathrm{A} \beta$ plaques, and innovative advancements in science have also made PET imaging possible in small animals (Chatziioannou, 2002; Manook et al., 2012). For example, [11C] PIB, [F-18] Florbetaben, and [F-18] Flutemetamol are some of the molecular imaging tracers used in PET imaging (Drzezga, 2010; Son et al., 2018). Previous studies on Tg2576 mice show that [11C] PIB tracer binding is very low (Klunk et al., 2005) or not observed at any age (Snellman et al., 2013). In our study, we used [F-18] Florbetaben (FBB) for $A \beta$ plaque quantification in transgenic mice.

\section{MATERIALS AND METHODS}

\section{Animals}

In total, 19 transgenic mice ( $\operatorname{Tg} 2576)$ were used the study. Mice were classified into two groups: Alzheimer's disease (AD) group and normal control group. The Alzheimer's group $(\mathrm{n}=12)$ were $\mathrm{Tg} 2576$ mice with C57BL/6 genetic strains expressing a human gene called APP containing the Swedish double mutation (K670N/M671L). The control group $(\mathrm{n}=7)$ had similar genetic background but without any mutation. The mice model used for this study is from the same line used previously in Kang's study (Son et al., 2018). The control group and AD group both consisted of mice from age groups of 5, 8 9, and 12 months. All mice were sacrificed for pathology tests after PET imaging. The mice were sacrificed on the same day as imaging for correlation analysis between pathological findings and PET images. Animal studies were conducted in accordance with the policies of the institutional animal committee (Dong-A university, Busan, South Korea, IRB number: LML 16-970). The mice were kept under 12-hour light-dark cycle with continuous access to food and water. The room where mice were kept was always maintained at a temperature of $21 \pm$ $2^{\circ} \mathrm{C}$ and a relative humidity of $50 \%$ respectively.

\section{Behavioral test}

The Y-maze was used to test spontaneous alteration in mice. The apparatus was a black cardboard material with 3 arms which resembled the letter $Y(32 \mathrm{~cm} \times 610 \mathrm{~cm} \times$ $26 \mathrm{~cm})$. The arms were at an angle of $120^{\circ}$ from each other. The control $\mathrm{AD}$ and control groups were subjected to the maze test. All behavior tests were performed in the same room at a similar time to minimize variations in result and maintain consistency of the study.

Prior to starting the test, the arms were randomly designated as A, B, and C. The mice were carefully placed on the center of the Y-maze and could freely explore all three arms of the maze for 5 minutes. The arm entries throughout 5 minutes were recorded in a sequence manually by the researcher. In a condition where the mouse only entered half way through an arm, the entry was considered invalid and was hence omitted. The spontaneous alteration was measured in percentage using the following formula (Miedel et al., 2017).

Spontaneous alteration $\%=($ total No. of alterations $) /$ (total No. of arm entry-2) $\times 100$

A spontaneous alteration was defined as three consecutive entries to three different arms (example: $\mathrm{ABC}, \mathrm{ACB}, \mathrm{BCA}$, and so on). 


\section{Immunohistochemistry staining}

The mice were sacrificed by transcardial perfusion with $0.5 \%$ sodium nitrate and heparin $(10 \mathrm{U} / \mathrm{mL})$ solution. The brain was extracted from the skull and post-fixed in $4 \%$ paraformaldehyde. The samples were stored overnight in $30 \%$ sucrose solution until it sank at $4^{\circ} \mathrm{C}$. Prior to staining, brain samples were cryosectioned into $30-\mu \mathrm{M}$-thick coronal sections on a sliding microtome. Immunohistochemical staining was performed on the cryosectioned tissue of mouse brain with methods previously described in Choi's study (Choi et al., 2018). The tissue sections were then washed with phosphatebuffered saline solution and incubated with primary antibody against A $\beta$ (1:100; Abcam, Cambridge, MA, USA) overnight at room temperature. On the following day, sections were washed with phosphate-buffered saline which contained $0.5 \%$ bovine serum albumin and then incubated with biotinylated secondary antibody. An avidin-biotin complex kit (Vectastain ABC kit; Vector Laboratories, Burlingame, CA, USA) was used to process the sections. The processed sections were incubated with $0.5 \%$ diaminobenzidine- $\mathrm{HCl}$ and $0.003 \%$ hydrogen peroxide in $0.1 \mathrm{M}$ phosphate buffer to view bound anti-serum. The sections were then washed with $0.1 \mathrm{M}$ phosphate buffer to stop the reaction by diaminobenzidine$\mathrm{HCl}$. The tissue sections were subsequently mounted on slides containing gelatin coats, and $\mathrm{A} \beta$ plaques were observed under bright-field microscope (Nikon, Tokyo, Japan) at $40 \times$, $100 \times$, and $200 \times$ magnification. $A \beta$ positive cells in cortex tissue were counted using light microscope (Nikon) under $400 \times$ objective of $250 \mu \mathrm{M}$.

\section{PET/CT imaging}

Analysis of PET images was conducted using fusion toolbox in PMOD software version 3.6.0 (PMOD Technologies, Zurich, Switzerland). The standard uptake value ratio (SUVR) was calculated by the volume of interest (VOI) based method. The reference region was the cerebellar cortex. The SUVR was calculated by dividing the mean SUV value of the cerebellum and the values in the cortex region of each mouse brain.

Siemens Inveon PET scanner (Siemens Medical Solutions, Malvern, PA, USA) was used for micro-PET imaging of all mice. The mice were fasted for 12 hours prior to imaging to increase [F-18] Fluorodeoxyglucose (FDG) uptake and image contrast (Fueger et al., 2006). Body temperature was maintained at $37^{\circ} \mathrm{C}$ with the help of heating pad embedded with a temperature control function. Contrast injection of $200 \mu \mathrm{Ci}$ of $0.1 \mathrm{~mL}$ [F-18] FDG was injected into the tail vein. The mice rested for at least 30 mins before PET imaging to allow adequate time for tracer uptake. After the resting time, PET acquisition was performed for 30 mins (350 650 keV). The acquired data were arranged into 3D sinograms and reassembled using OSEM3D method. The mice were kept under constant anesthesia ( $2 \%$ isoflurane in $100 \%$ oxygen) during the time of injection and PET scan.

[F-18]-FBB imaging was performed in all mice within a few days of time interval. Contrast injection of $200 \mu \mathrm{Ci}$ of $0.1 \mathrm{~mL}$ was injected intravenously through the tail. The lights were turned off during the [F-18]-FBB injection time since [F-18]-FBB tracer is sensitive to light. The PET acquisition protocol was identical to the [F-18] FDG imaging.

\section{Statistical analysis}

All statistical analyses were performed using MedCalc 18.9.1 (company, location). A $P$-value of less than 0.05 was considered to be statistically significant.

\section{RESULTS}

\section{Cognitive function of normal vs. Alzheimer mouse}

In the normal control group, the Y-maze test score was $90.0 \%, 95.0 \%$, and $92.5 \%$ at 5, 8 9, and 12 months respectively. These results indicate no significant changes in cognitive function with respect to ageing. In contrast, the test scores in the $\mathrm{AD}$ group were $85.3 \%, 47.8 \%$, and $55.64 \%$ at 5, 8 9, and 12 months, respectively. The results showed a striking decline in cognition at 8 9 and 12 months compared to normal control mice (Fig. 1).

\section{Amyloid plaque deposition in relation to age}

The pathological analysis (Fig. 2) revealed that normal control mice did not show manifestation of amyloid plaque deposition examined microscopically on $40 \times, 100 \times$, and $200 \times$ magnifications until the age of 12 months. In the AD 
A

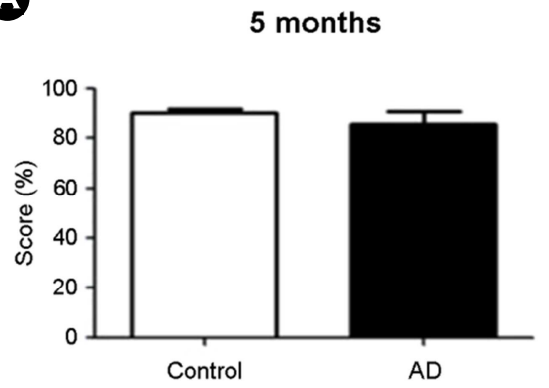

B

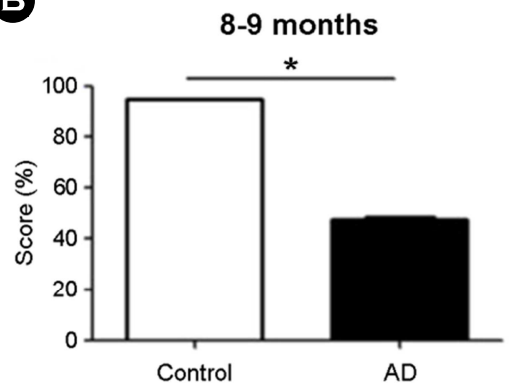

C

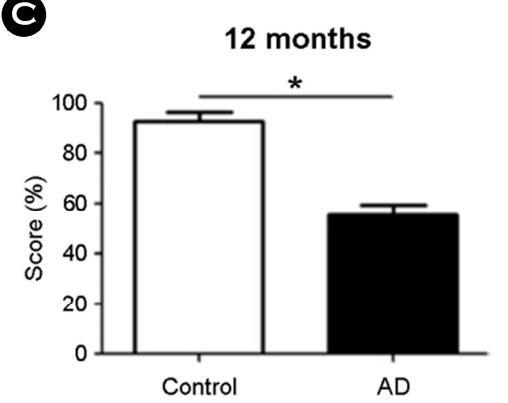

Fig. 1. Cognitive function test using behavioral test in normal control group and $\mathrm{AD}$ group $(* P<0.0001)$.

$40 x$

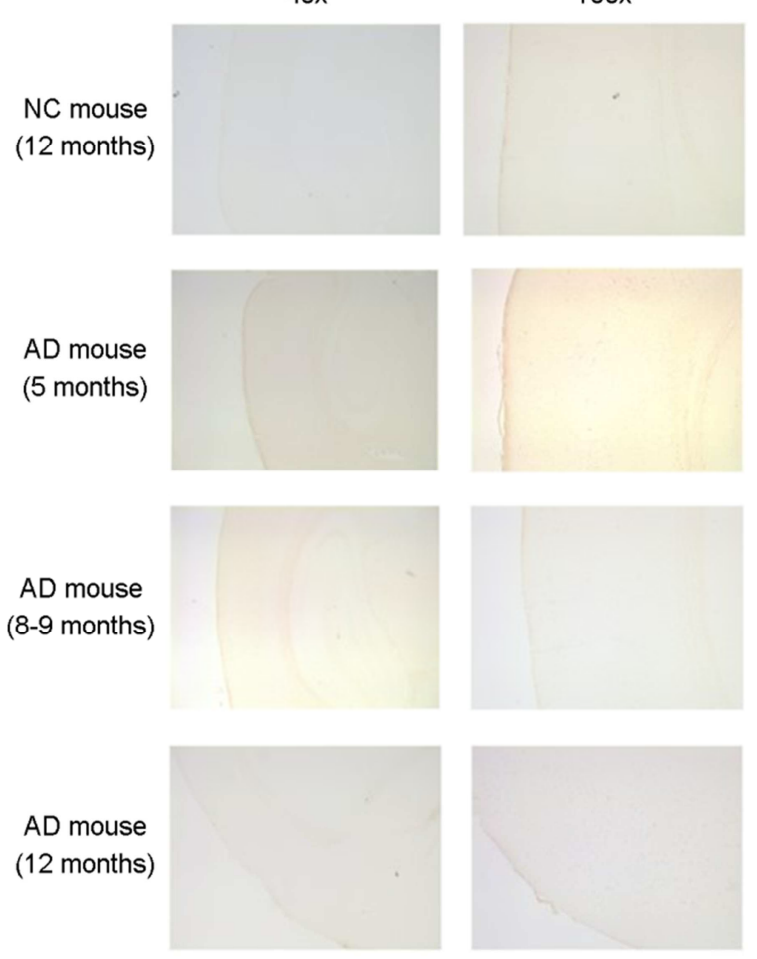

$200 x$
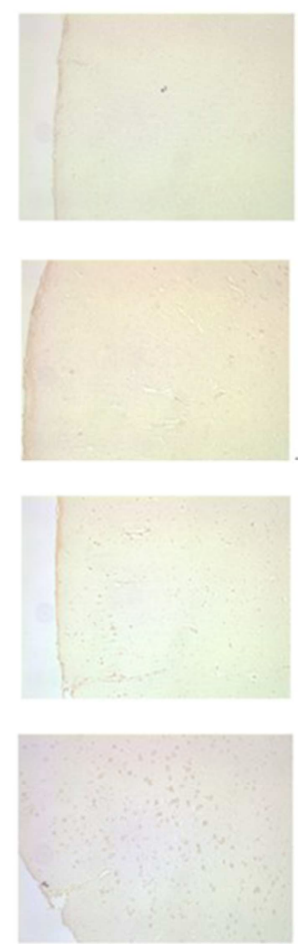

Fig. 2. Amyloid plaque deposition on brain tissue in relation to age. The $\mathrm{AD}$ mice aged 9 and 12 months have large quantities of amyloid plaque deposition in the cortex compared to 5 month old mice in the same group. The control mice showed no sign of plaque deposition at 12 months. group, plaque deposition was substantially high especially at the age of $8 \sim 9$ and 12 months. However, there was little to no amyloid plaque deposition in the $\mathrm{AD}$ group at the age of 5 months. The ratio of the total area of the amyloid protein in the normal control group was $0.03,0.06$, and 0.04 at 5 , $8 \sim 9$, and 12 months respectively. In the $\mathrm{AD}$ group, the ratio of the total area of amyloid protein was found to be $0.04,0.10$, and 0.14 , at 5, 8 9, and 12 months respectively (Fig. 3). The proportion of amyloid protein was statistically significant $(P<0.0001)$ in the AD group than control group.

\section{Analysis of PET images}

[F-18] FBB PET imaging was used for quantitative analysis of A $\beta$-plaque deposition. The SUVR values for mice of 5, $8 \sim 9$, and 12 months were $0.84,0.88$, and 0.82 , respectively in normal control mice group. There was no significant difference observed in SUVR with regard to age of mice. In the $\mathrm{AD}$ group, the SUVR values were 0.86, 0.87, and 0.99 for 5, 8 9, and 12-month old mice respectively. There was a statistically significant difference in SUVR values 

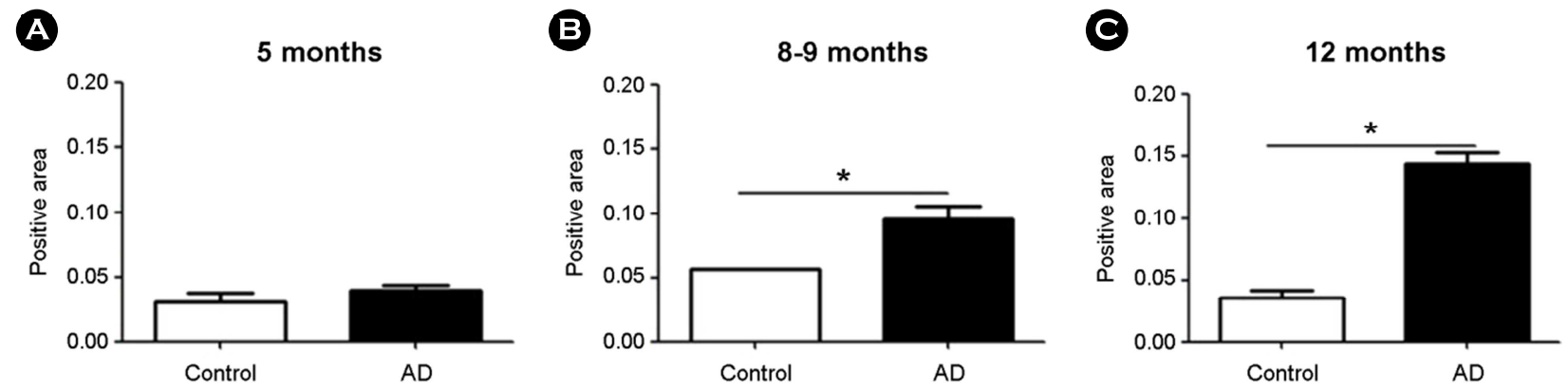

Fig. 3. Comparison of amyloid protein measured in brain tissue in normal control and $\mathrm{AD}$ groups $(* P<0.0001)$.
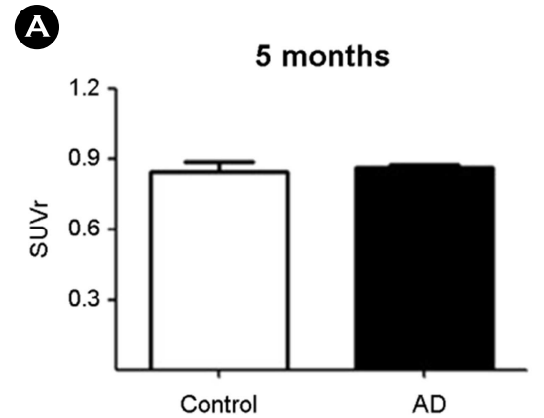

B

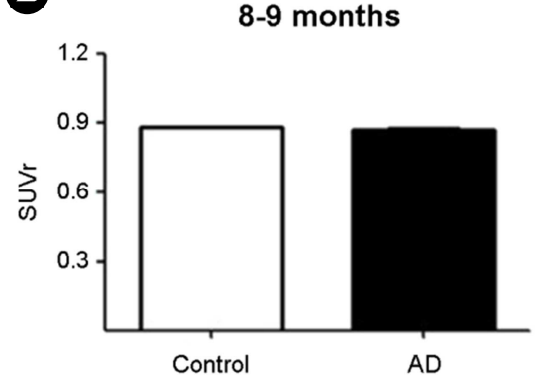

C

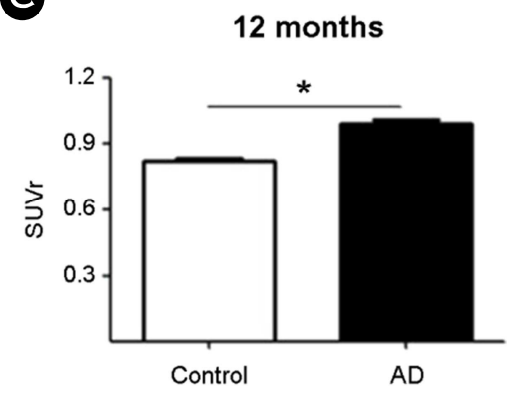

Fig. 4. Comparison of quantitative values measured with amyloid PET brain image using F-18 FBB $(* P=0.0007)$.

(A)

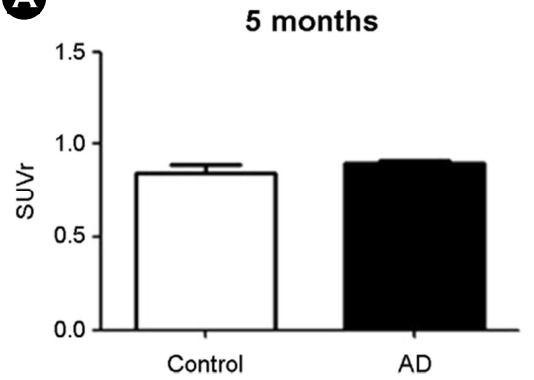

B

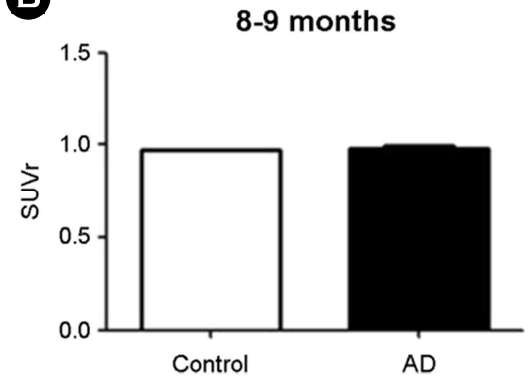

C

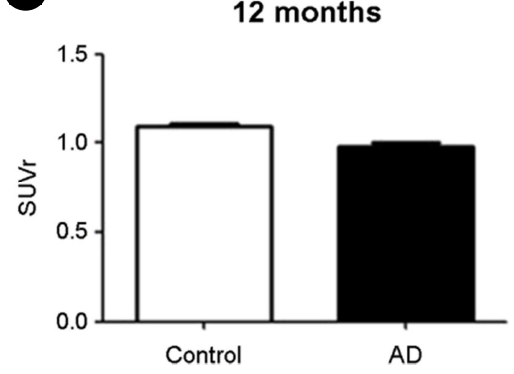

Fig. 5. Comparison of quantitative values measured by PET brain image using F-18 FDG.

with respect to the age of mice $(P=0.0007)$ in comparison to normal control group (Fig. 4).

[F-18] FDG PET imaging was used to detect glucose hypometabolism in $\mathrm{A} \beta$-plaques affected areas. In the normal control group, SUVR values were 0.96, 0.97, and 1.09 at 5, $8 \sim 9$, and 12 months, respectively. There were no drastic differences in SUVR in control with age. In the AD group, the SUVR values were $0.90,0.98$, and 0.98 at the same months and were not different from control $(P=0.09)$ (Fig. 5).

\section{Correlation analysis}

In the $\mathrm{AD}$ group, we analyzed the correlation between two age groups ( $8 \sim 9$, and 12 months), pathologic findings, cognitive function tests, ad amyloid PET findings. Amyloid PET images were strongly correlated pathological findings ( $r=0.7861, P=0.0024$ ) (Fig. 6A), but was negatively (but not significantly) correlated with cognitive function $(r=$ $-0.49 .1, P=0.1057$, Fig. 6B). Pathological findings for brain 

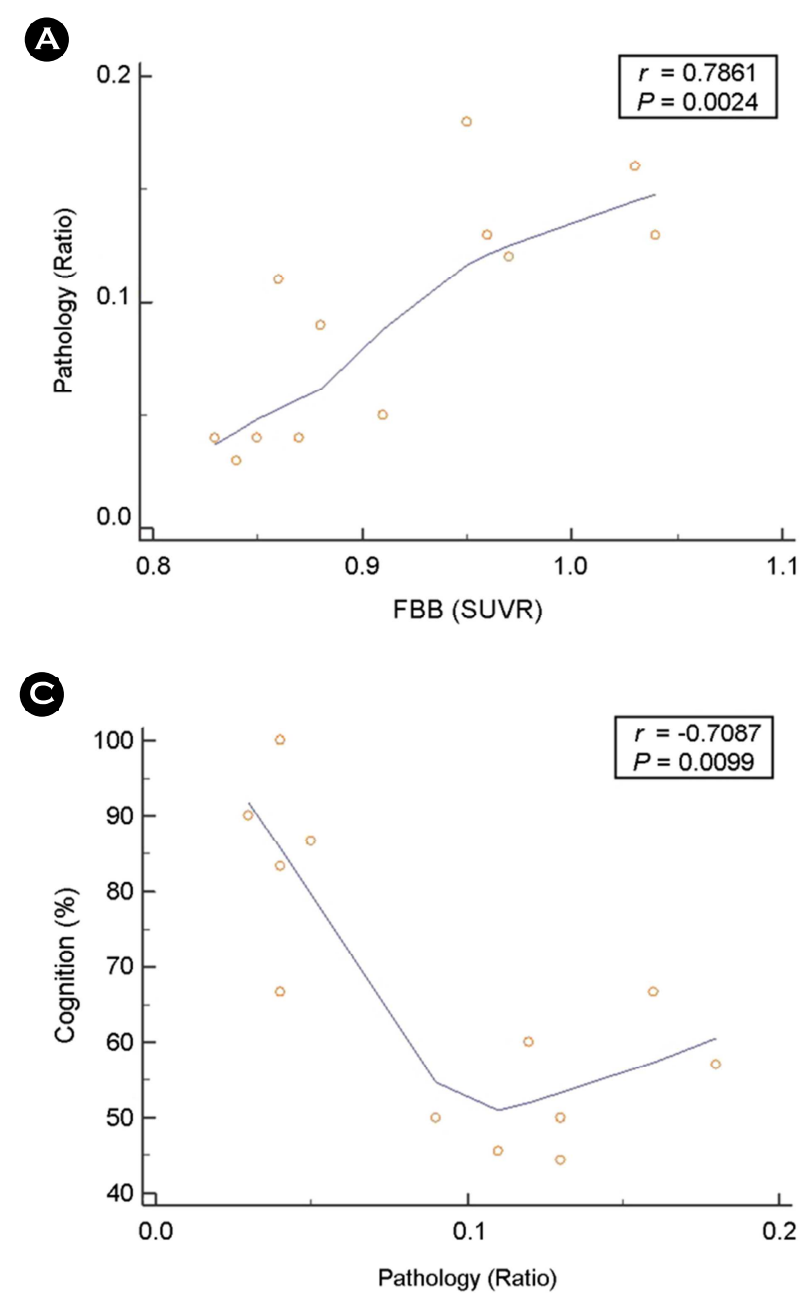

tissue showed a moderately negative correlation with cognitive function ( $r=-0.7087, P=0.0099)$ (Fig. 6C).

\section{DISCUSSION}

The AD model of APP transgenic mice and APP/PS1 biogenic mice are the only models that show $\mathrm{A} \beta$-plaque deposition along with progressive memory impairment (Ashe, 2001) and are widely used in Alzheimer's disease studies. We used transgenic mice ( $\mathrm{Tg} 2576$ ) excessively expressing human APP, containing Swedish double mutation (K670N/ M671L) and C57BL/6 genetic strains. This mouse line shows age-dependent $\mathrm{A} \beta$-plaques deposit around cortical and hippocampal areas (Hsiao et al., 1996; Christie et al., 2001). Other studies (Hsiao et al., 1996; Chapman et al., 1999; King et al., 1999; Pompl et al., 1999; Morgan et al., 2000) have

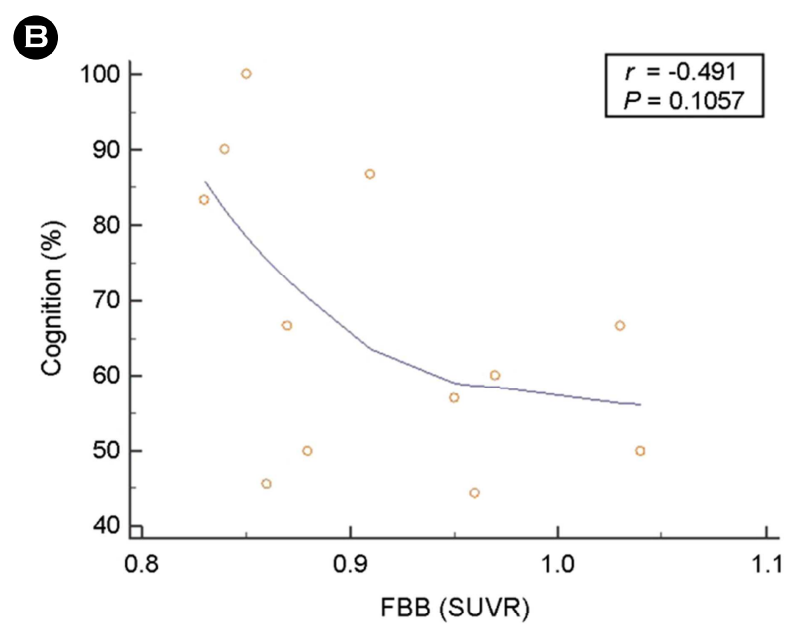

Fig. 6. Correlation analysis in AD mice group. (A) Correlation between the quantification value of [F-18] FBB PET and degree of amyloid deposition confirmed by pathology. (B) Correlation between cognition and [F-18] FBB PET result. (C) Correlation between cognition and pathology findings. (The line in the graph represents trend line).

reported cognitive defects in $\mathrm{Tg} 2576$ mice as early as 3 months and as late as 15 months (Ashe, 2001). Identifying the onset of memory impairment in APP transgenic mouse is difficult (Ashe, 2001). An early study in APP transgenic mouse with a Swedish mutation reported that memory impairment becomes obvious at age 9 months and older and is associated with $A \beta$-plaques deposit in the brain (Hsiao et al., 1996). Our findings are consistent with this previous work. $\mathrm{A} \beta$-plaque deposits in the cortex were negatively correlated with cognition. (Fig. 6C). Compared to normal control mice, the amount of $\mathrm{A} \beta$-plaques deposit was high in $8 \sim 9$ and 12 month old mice (Fig. 3).

In nuclear medicine, PET scans are a useful and safe tool for in vivo assessment of the brain for diagnosis of diverse tissues. [11C] PIB, [F-18] Florbetaben and [F-18] Flutemetamol are widely used radioactive tracers for in vivo visuali- 
zation of A $\beta$-plaques deposits (Drzezga, 2010; Son et al., 2018). We used two types of tracers, [F-18] FBB and [F-18] FDG tracer in our study. The [F-18] FBB tracer was used for the quantification of $\mathrm{A} \beta$-plaque deposition in the cortex of mouse brain. The [F-18] FBB PET image analysis showed a positive correlation between SUVRs and age of mice ( $r=$ 0.85). A difference in SUVR between control and AD mouse could be seen clearly at 12 months. Until 8 9 months of age, SUVR uptake in AD was similar to control. The [F-18] FBB SUVR analysis showed a strong positive correlation $(r=$ 0.83 ) with pathology results even though the immunostaining showed high $\mathrm{A} \beta$-plaques deposition from 9 months of age. [F-18] FDG was used as second tracer, and [F-18] FDG PET image analysis did not show any apparent differences in glucose hypometabolism in $\mathrm{AD}$ mice group across all age groups. This may be due to the limited amount of samples and reduced variance in age groups.

Several studies have used transgenic mice to study agedependent A $\beta$-plaques (Kawarabayashi et al., 2001), cognitive deficits (Moran et al., 1995) and correlation between age-dependent $\mathrm{A} \beta$-plaques deposition and cognition (Hsiao et al., 1996; Takeuchi et al., 2000; Ashe, 2001; Gordon et al., 2001) similar to our study. However, our study used [F-18] FBB PET imaging in addition to immunostaining for agedependent quantification of $\mathrm{A} \beta$ plaques and cognition.

\section{ACKNOWLEDGEMENT}

This research was supported by the project at Institute of Convergence Bio-Health, Dong-A University funded by Busan Institute of S\&T Evaluation and Planning.

\section{CONFLICT OF INTEREST}

No potential conflict of interest relevant to this article was reported.

\section{REFERENCES}

Aizenstein HJ, Nebes RD, Saxton JA, Price JC, Mathis CA, Tsopelas ND, Ziolko SK, James JA, Snitz BE, Houck PR. Frequent amyloid deposition without significant cognitive impairment among the elderly. Archives of Neurology. 2008. 65: 1509 $-1517$
Ashe KH. Learning and memory in transgenic mice modeling alzheimer's disease. Learning \& Memory. 2001. 8: 301-308.

Chapman PF, White GL, Jones MW, Cooper-Blacketer D, Marshall VJ, Irizarry M, Younkin L, Good MA, Bliss T, Hyman BT. Impaired synaptic plasticity and learning in aged amyloid precursor protein transgenic mice. Nature Neuroscience. 1999. 2: 271 .

Chatziioannou AF. Pet scanners dedicated to molecular imaging of small animal models. Molecular Imaging \& Biology. 2002. 4: 47-63.

Choi GE, Yoon S-Y, Kim J-Y, Kang D-Y, Jang YJ, Kim HS. Autophagy deficiency in myeloid cells exacerbates eosinophilic inflammation in chronic rhinosinusitis. Journal of Allergy and Clinical Immunology. 2018. 141: 938-950. e912.

Christie R, Yamada M, Moskowitz M, Hyman B. Structural and functional disruption of vascular smooth muscle cells in a transgenic mouse model of amyloid angiopathy. The American Journal of Pathology. 2001. 158: 1065-1071.

Drzezga A. Amyloid-plaque imaging in early and differential diagnosis of dementia. Annals of Nuclear Medicine. 2010. 24: 55 $-66$.

Elder GA, Gama Sosa MA, De Gasperi R. Transgenic mouse models of alzheimer's disease. The Mount Sinai Journal of Medicine. 2010. 77: 69-81.

Fueger BJ, Czernin J, Hildebrandt I, Tran C, Halpern BS, Stout D, Phelps ME, Weber WA. Impact of animal handling on the results of 18f-fdg pet studies in mice. Journal of Nuclear Medicine. 2006. 47: 999.

Gordon MN, King DL, Diamond DM, Jantzen PT, Boyett KV, Hope CE, Hatcher JM, DiCarlo G, Gottschall WPE, Morgan D. Correlation between cognitive deficits and $A \beta$ deposits in transgenic app+ ps1 mice. Neurobiology of Aging. 2001. 22: 377-385.

Holtzman DM, Morris JC, Goate AM. Alzheimer's disease: The challenge of the second century. Science Translational Medicine. 2011. 3: 77 sr71-77sr71.

Hsiao K, Chapman P, Nilsen S, Eckman C, Harigaya Y, Younkin $S$, Yang F, Cole G. Correlative memory deficits, $A \beta$ elevation, and amyloid plaques in transgenic mice. Science. 1996. 274: 99-103.

Kawarabayashi T, Younkin LH, Saido TC, Shoji M, Ashe KH, Younkin SG. Age-dependent changes in brain, csf, and plasma amyloid $\beta$ protein in the tg2576 transgenic mouse model of alzheimer's disease. Journal of Neuroscience. 2001. 21: 372 $-381$. 
Khachaturian ZS. Diagnosis of alzheimer's disease. Archives of Neurology. 1985. 42: 1097-1105.

King DL, Arendash GW, Crawford F, Sterk T, Menendez J, Mullan MJ. Progressive and gender-dependent cognitive impairment in the appsw transgenic mouse model for alzheimer's disease. Behavioural. Brain Research. 1999. 103: 145-162.

Klunk WE, Engler H, Nordberg A, Bacskai BJ, Wang Y, Price JC, Bergström M, Hyman BT, Långström B, Mathis CA. Imaging the pathology of alzheimer's disease: Amyloid-imaging with positron emission tomography. Neuroimaging Clinics. 2003. 13: 781-789.

Klunk WE, Lopresti BJ, Ikonomovic MD, Lefterov IM, Koldamova RP, Abrahamson EE, Debnath ML, Holt DP, Huang G-F, Shao L. Binding of the positron emission tomography tracer pittsburgh compound-b reflects the amount of amyloid- $\beta$ in alzheimer's disease brain but not in transgenic mouse brain. Journal of Neuroscience. 2005. 25: 10598-10606.

Kuntner C, Kesner AL, Bauer M, Kremslehner R, Wanek T, Mandler M, Karch R, Stanek J, Wolf T, Müller M, Langer O. Limitations of small animal pet imaging with [18f]fddnp and fdg for quantitative studies in a transgenic mouse model of alzheimer's disease. Molecular Imaging and Biology. 2009. 11: 236-240.

Manook A, Yousefi BH, Willuweit A, Platzer S, Reder S, Voss A, Huisman M, Settles M, Neff F, Velden J. Small-animal pet imaging of amyloid-beta plaques with [11c] pib and its multimodal validation in an app/ps1 mouse model of alzheimer's disease. PloS One. 2012. 7: e31310.

Miedel CJ, Patton JM, Miedel AN, Miedel ES, Levenson JM. Assessment of spontaneous alternation, novel object recognition and limb clasping in transgenic mouse models of amyloid$\beta$ and tau neuropathology. Journal of Visualized Experiments: JoVE. 2017.

Molinuevo JL, Ayton S, Batrla R, Bednar MM, Bittner T, Cummings J, Fagan AM, Hampel H, Mielke MM, Mikulskis A. Current state of alzheimer's fluid biomarkers. Acta Neuropathologica. 2018. 1-33.

Moran PM, Higgins LS, Cordell B, Moser PC. Age-related learning deficits in transgenic mice expressing the 751-amino acid isoform of human beta-amyloid precursor protein. Proceedings of the National Academy of Sciences. 1995. 92: 5341-5345.

Morgan D, Diamond DM, Gottschall PE, Ugen KE, Dickey C, Hardy J, Duff K, Jantzen P, DiCarlo G, Wilcock D. A $\beta$ peptide vaccination prevents memory loss in an animal model of alzheimer's disease. Nature. 2000. 408: 982.
Pompl PN, Mullan MJ, Bjugstad K, Arendash GW. Adaptation of the circular platform spatial memory task for mice: Use in detecting cognitive impairment in the appsw transgenic mouse model for alzheimer's disease. Journal of Neuroscience Methods. 1999. 87: 87-95.

Rowe CC, Bourgeat P, Ellis KA, Brown B, Lim YY, Mulligan R, Jones G, Maruff P, Woodward M, Price R. Predicting alzheimer disease with $\beta$-amyloid imaging: Results from the australian imaging, biomarkers, and lifestyle study of ageing. Annals of Neurology. 2013. 74: 905-913.

Snellman A, López-Picón FR, Rokka J, Salmona M, Forloni G, Scheinin M, Solin O, Rinne JO, Haaparanta-Solin M. Longitudinal amyloid imaging in mouse brain with 11c-pib: Comparison of app23, tg2576, and appswe-ps1de9 mouse models of alzheimer disease. J Nucl Med. 2013. 54: 1434-1441.

Son HJ, Jeong YJ, Yoon HJ, Lee SY, Choi G-E, Park J-A, Kim MH, Lee KC, Lee YJ, Kim MK. Assessment of brain betaamyloid deposition in transgenic mouse models of alzheimer's disease with pet imaging agents 18 f-flutemetamol and 18 f-florbetaben. BMC Neuroscience. 2018. 19: 45.

Takeuchi A, Irizarry MC, Duff K, Saido TC, Ashe KH, Hasegawa M, Mann DM, Hyman BT, Iwatsubo T. Age-related amyloid $\beta$ deposition in transgenic mice overexpressing both alzheimer mutant presenilin 1 and amyloid $\beta$ precursor protein swedish mutant is not associated with global neuronal loss. The American Journal of Pathology. 2000. 157: 331-339.

Tijms BM, Vermunt L, Zwan MD, van Harten AC, van der Flier WM, Teunissen CE, Scheltens P, Visser PJ, ADNI. Pre-amyloid stage of alzheimer's disease in cognitively normal individuals. Annals of Clinical and Translational Neurology. 2018. 5: 1037 -1047 .

Villemagne VL, Pike KE, Darby D, Maruff P, Savage G, Ng S, Ackermann U, Cowie T, Currie J, Chan S. A $\beta$ deposits in older non-demented individuals with cognitive decline are indicative of preclinical alzheimer's disease. Neuropsychologia. 2008. 46: 1688-1697.

https://doi.org/10.15616/BSL.2019.25.1.7

Cite this article as: Thapa N, Jeong YJ, Kang H, Choi GE, Yoon HJ, Kang DY. A Comparative Study of [F-18] Florbetaben (FBB) PET Imaging, Pathology, and Cognition between Normal and Alzheimer Transgenic Mice. Biomedical Science Letters. 2019. 25: 7-14. 